Gut, 1987, 28, S1, 135-138

\title{
Modifications in ornithine decarboxylase and diamine oxidase in small bowel mucosa of starved and refed rats
}

\author{
L D'AGOSTINO, B DANIELE, S PIGNATA, M V BARONE, G D'ARGENIO, \\ AND G MAZZACCA
}

From the Cattedra di Malattie dell' Apparato Digerente, 2a Facolta' di Medicina, Napoli, Italy.

SUMMARY Starvation followed by refeeding, which provides a model of intestinal adaptation characterised by proliferative and biochemical changes, was used to clarify the biological roles of ornithine decarboxylase (ODC) and diamine oxidase (DAO) - enzymes involved in polyamines metabolism. Ornithine decarboxylase and DAO were assayed in the proximal and distal small bowel mucosa of 55 rats, starved for four days and then refed. Rats (five per day) were killed after four days' starvation and at days $1,2,3,4,5,6,7,8,10$ and 12 of refeeding. ODC, whose specific activity was similar in both intestinal segments, almost disappeared after starvation and showed a biphasic response during refeeding. High values were found on day 3 of refeeding in the proximal, and on day 4 in the distal small bowel; thereafter, they decreased gradually to be followed by a further significant increase during the last two days of the experiment. Diamine oxidase specific activity increased after starvation despite a very low total DAO activity in both intestinal segments. Refeeding induced a gradual recovery of DAO total activity. Diamine oxidase specific activity also reverted gradually to control values after five days of refeeding. These data confirm the prominence of ODC in the replication processes and suggest that intestinal DAO may not play a major role in enterocyte replication.

Several models of intestinal adaptation are associated with biochemical and morphological changes in the small bowel mucosa. Starvation and refeeding - for example, cause marked modifications in the proliferative indices. In particular, starvation induces a marked fall in the crypt cell production rate and in plasma enteroglucagon levels, while refeeding reverses this pattern. ${ }^{1}$

In this study we investigated the effects of starvation and refeeding on rat small bowel mucosal ornithine decarboxylase (ODC) and diamine oxidase (DAO) activities - enzymes involved in polyamine metabolism and therefore in cell replication. ${ }^{2}$ The overall importance of intestinal DAO, however remains to be defined. ${ }^{3}$ In particular, the fact that it is located mainly in the ileum ${ }^{4}$ and is released directly from the enterocytes into the plasma by IV heparin ${ }^{56}$ casts doubts on the exclusivity of its role in enterocyte replication. The behaviour of these enzymes in this

Address for correspondence: Luciano D'Agostino, MD, Divisione di Gastroenterologia, 2a Facolta' di Medicina, via S Pansini 5, 80131 Napoli, Italy. experimental model may better clarify their role in the mechanisms involved in intestinal epithelial adaptation. Since the changes in rat jejunum and ileum in response to starvation and refeeding are different, ${ }^{1}$ and as DAO activity is higher in the distal rat small bowel than in the proximal part, ${ }^{4}$ we measured the changes in ODC and DAO activities in both segments. Sucrase, a brush border enzyme which is linked to mature enterocytes and whose activity is rapidly affected by food intake, ${ }^{7-9}$ was also assayed.

\section{Methods}

\section{ANIMALS}

Sixty male Wistar rats weighing $240-280 \mathrm{~g}$ were used. They were divided into groups of five, housed in wirebottomed cages to prevent coprophagia, and fed a pelleted diet (MINGNINI SpA, Italy). They were weighed daily and their food intake was recorded. For 10 days before the experiment began and throughout the experimental period, the animals were kept in 
constant light conditions to avoid rhythmic changes in food intake and possibly also in sucrase ${ }^{10}$ and ODC $^{11}$ activities.

\section{EXPERIMENTAL DESIGN}

All the other groups of rats with the exception of the control group, were starved for four days. One group was killed before refeeding (day 0); the other groups were killed at days $1,2,3,4,5,6,7,8,10$ and 12 of refeeding.

ORNITHINE DECARBOXYLASE, DIAMINE

OXIDASE AND SUCRASE ASSAYS

The rats were anaesthetised with diethyl ether and then decapitated. The small bowel was stripped of its mesentery from the ligament of Treitz to the ileocaecal junction and removed. The small intestine was next divided into two segments of equal length, gently washed with cold saline and opened longitudinally.

The mucosa was carefully scraped from each segment, homogenised with a Ystral GmbH homogeniser (West Germany) in $0.1 \mathrm{M} / 1$ sodium phos-

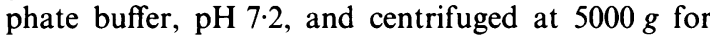
three minutes at $4{ }^{\circ} \mathrm{C}$, with a Beckman TJR centrifuge (USA).

Because of its short half-life ${ }^{12}$ the ODC assay was carried out immediately to avoid loss of enzyme activity. The DAO, sucrase and protein assays were done within one week on supernatants stored at $-20^{\circ} \mathrm{C}$. Centrifugation, which was of help in the ODC assay, resulted in a slight decrease in DAO and sucrase activities in the supernatant, with respect to the homogenate. Ornithine decarboxylase was assayed according to Djuhruus, ${ }^{13}$ DAO as described in our previous study, ${ }^{4}$ sucrase by Dahlqvist's method ${ }^{14}$ and proteins by Lowry's method. ${ }^{15}$

Ornithine decarboxylase units are expressed as pM of putrescine released in one hour at $37^{\circ} \mathrm{C}, \mathrm{pH} \mathrm{7.2}$; DAO units as $\mathrm{nM}$ of putrescine dihydrochloride oxidised in one hour at $37^{\circ} \mathrm{C}, \mathrm{pH} 7.2$; sucrase as $\mu \mathrm{M}$ of glucose released in one minute at $37^{\circ} \mathrm{C}$, pH 7.4.

\section{STATISTICAL ANALYSIS}

A two tailed unpaired Student's $t$ test was used. Results, expressed as mean \pm SD were considered to be statistically significant when $\mathrm{p}<0.05$.

\section{Results}

FOOD INTAKE

The mean food intake for each rat before starvation was $25 \cdot 0 \pm 4 \cdot 3 \mathrm{~g} /$ day. The mean food intake after refeeding was $25 \cdot 3 \pm 3.1 \mathrm{~g} /$ day.

BODY WEIGHT

The mean initial body weight of the rats $(262 \pm 13 \mathrm{~g})$
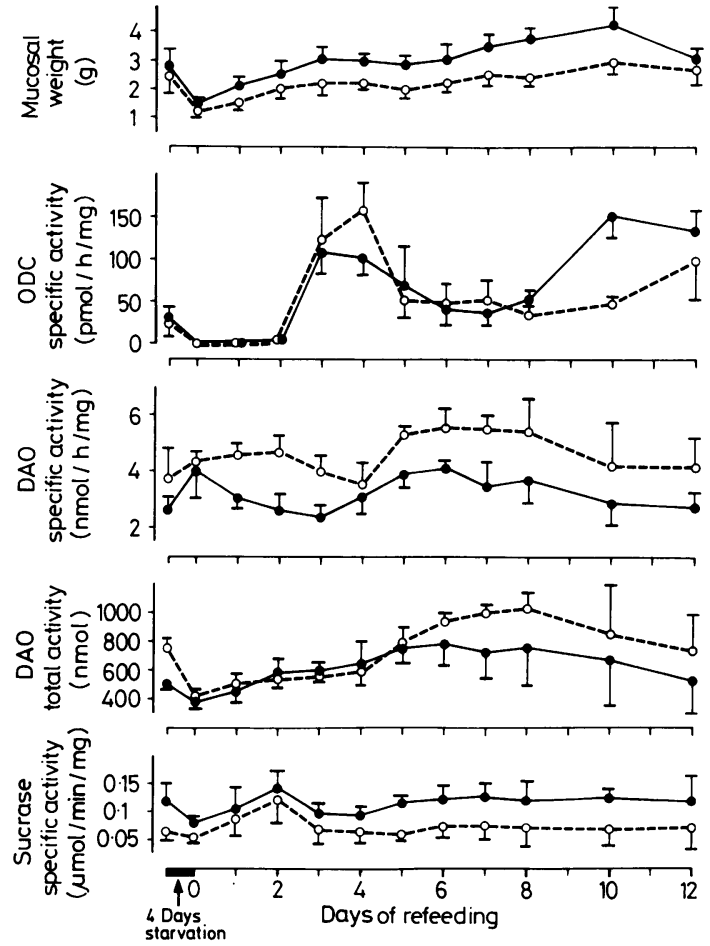

Figure Changes in mucosa wet weight, $O D C$ specific activity, DAO specific activity, DAO total activity, and sucrase specific activity in proximal (O) and distal (O) rat small bowel during four days starvation and after refeeding - mean values \pm standard deviations.

decreased to $204 \pm 12 \mathrm{~g}(\mathrm{p}<0.001)$ after four days starvation. Following refeeding, however, the mean body weight increased steadily returning to basal values after five days' refeeding. It then slowly increased until day 8 but remained unchanged thereafter. The results for small bowel mucosal weight, ODC, DAO and sucrase, are shown in the Figure.

\section{MUCOSAL WEIGHT}

The mean mucosal wet weight (MWW) at the beginning of the experiment was $2.7 \pm 0.7 \mathrm{~g}$ in the proximal, and $2.4 \pm 0.5 \mathrm{~g}$ in the distal, small bowel and decreased to $1.4 \pm 0.05 \mathrm{~g}$ and $1.3 \pm 0.1 \mathrm{~g}$ $(p<0.001)$ respectively, after starvation. After refeeding, the MWW increased consistently, returning to basal values after three days in the proximal, and after seven days in the distal, segment and reached a peak at day 10 . At this time, MWW showed a marked increase with respect to control values in both segments, but this was significantly higher $(p<0.001)$ in the proximal $(59.8 \%)$, than in the distal, segment $(20 \cdot 1 \%)$ 
ORNITHINE DECARBOXYLASE

After starvation, and during the first two days of refeeding ODC specific activity (sa) was almost zero in both intestinal segments, but a significant increase ( $p<0.001$ ) was recorded on days $3,4,5$. The peak value $(109 \pm 20 \mathrm{U} / \mathrm{mg})$ was found on day 3 in the proximal and on day $4(156 \pm 41 \mathrm{U} / \mathrm{mg})$ in the distal small bowel. Thereafter, the values decreased gradually so that by day 6 , an ODC sa very similar to that in control group (proximal: $36 \cdot 7 \pm 4.5 \mathrm{U} / \mathrm{mg}$; distal: $16.5 \pm 7 \mathrm{U} / \mathrm{mg}$ ), was found. Then, over the last two test days of the experiment, a new and significant increase $(p<0.001)$ occurred in both the proximal (peak value: $150 \pm 25 \mathrm{U} / \mathrm{mg}$ ) and distal (peak value: $101 \pm 45 \mathrm{U} / \mathrm{mg}$ ) small bowel mucosa.

\section{DIAMINE OXIDASE}

Diamine oxidase sa increased after starvation more so in the proximal $(4.0 \pm 0.8 \mathrm{U} / \mathrm{mg})$ than in the distal small bowel $(4.3 \pm 0.5 \mathrm{U} / \mathrm{mg})$. Control values were $2.6 \pm 0.5 \mathrm{U} / \mathrm{mg}$ in the proximal and $3.8 \pm 0.5 \mathrm{U} / \mathrm{mg}$ in the distal tract. Nevertheless, DAO total activity decreased sharply in both segments after starvation, the percentage decrease being higher in the distal $(47.5 \%)$ than in the proximal $(26.2 \%)$ small bowel. During the first three days of refeeding, DAO sa remained high in the distal but decreased in the proximal segment and then returned to control values. On days 5 to 8 , DAO sa was higher than control values - mainly in the distal small bowel mucosa. While DAO sa was consistently higher in the distal than in the proximal intestinal tract, DAO total activity was comparable in both study segments during the first five days of refeeding. Then, in the following days, higher activities were found in the distal than in the proximal tract.

\section{SUCRASE}

After four days' starvation, sucrase sa decreased significantly $(\mathrm{p}<0.001)$ in both the proximal $(0.075 \pm 0.01 \mathrm{U} / \mathrm{mg}$; basal values: $0.12 \pm 0.03 \mathrm{U} / \mathrm{mg})$ and distal tract $(0.055 \pm 0.01 \mathrm{U} / \mathrm{mg}$; basal values: $0.065 \pm 0.01 \mathrm{U} / \mathrm{mg})$. After the first day of refeeding, however, the sa of this enzyme increased promptly to exceed basal values on day 2 ; it then returned to control values on day 3 and remained unchanged thereafter.

\section{Discussion}

In this study, the behaviour of ODC in the proximal and distal small bowel is, in some ways, similar to that already described in other experimental models of intestinal adaptation. ${ }^{16}$ The modifications in DAO activity are considerable however and suggest that this enzyme is not exclusively involved in cell replication. Four days' starvation led to a loss of body weight and a reduction in small bowel MWW. After this period, when there is known to be a marked decrease in crypt cell production rate (CCPR) and in plasma enteroglucagon, ${ }^{1}$ in both segments studied ODC sa approached zero while DAO sa was significantly increased. Nevertheless, DAO total activity was clearly diminished when compared with that found in normally fed rats. Similar results for DAO sa were seen in rats treated with difluoromethyl ornithine, a specific and irreversible ODC inhibitor. ${ }^{17}$

These data indicate that the reduction in MWW induced by starvation is associated with almost zero levels of ODC sa. This finding is consistent with the belief that ODC plays a primary role in cell replication. Conversely, the increase in DAO sa and the marked fall in DAO total activity suggest that DAO is spared more than other proteins and this argues against an exclusive role for DAO in cell proliferation. ODC sa showed two rises after refeeding - the first within a few days and a second towards the end of the experiment, when a parallel increase in MWW was also recorded. The changes observed over the last few days of the experiment were more intense in the proximal than in the distal tract; further studies are necessary to establish whether these changes are an expression of mucosal hyperplasia. It is interesting to note that a biphasic trend of ODC has been described previously in an experimental model of intestinal carcinogenesis. ${ }^{18}$ The present data, therefore, may strengthen the connection between intestinal hyperplasia and carcinogenesis. ${ }^{19}$ Throughout the experiment, the changes in DAO sa did not correspond with modifications in any of the other parameters: in particular, the changes in DAO sa were completely different from those for ODC sa. DAO total activity was higher in the distal tract than in the proximal, intestinal tract. However, comparable levels of DAO total activity were found in both intestinal segments after starvation and during the first few days of refeeding, and this is consistent with a more marked loss of DAO activity in the distal small bowel. Nonetheless, DAO sa was constantly higher in the distal than in the proximal small bowel because of a faster protein recovery in the proximal tract.

The DAO changes in this study were different from those described in other studies in which different models of intestinal adaptation were used. ${ }^{16}$ This is probably explained by the fact that during starvation and refeeding, the modifications in cell replication are different from those induced by small bowel resection or chemotherapy.

Sucrase sa decreased during starvation but showed a prompt recovery during refeeding. These findings 
confirm that sucrase activity is strictly dependent on food intake - as concluded by others. ${ }^{7-9}$

In conclusion, our data confirm that ODC plays a specific role in enterocytic replication processes and shows a biphasic response. The first rise is connected with mucosal recovery and the second, probably with mucosal hyperplasia. Conversely, in this experimental model, DAO behaviour was not in keeping with its supposed exclusive role in enterocyte replication.

One suggested function of this enzyme in the small bowel is in the regulation of exogenous and endogenous amine (histamine and putrescine) concentrations. This hypothesis, supported by the unusual intestinal location of DAO and by its releasibility by heparin from enterocytes at the villous tips, requires further study.

The authors thank Prof M Romano and Dr M A Santacroce for helpful suggestions and Mr P Esposito for technical assistance.

\section{References}

1 Goodlad RA, Al-Mukhtar MYT, Ghatei MA, Bloom SR, Wright NA. Cell proliferation, plasma enteroglucagon and plasma gastrin levels in starved and refed rats. Virchows Arch 1983; 43: 55-62.

2 Jänne J, Pösö H, Raina A. Polyamines in rapid growth and cancer. Biochim Biophys Acta 1978; 473: 241-93.

3 Biegański T. Biochemical, physiological and pathophysiological aspects of intestinal Diamine oxidase. Acta Physiol Pol 1983; 34: 139-53.

4 D'Agostino L, D'Argenio G, Ciacci C, Daniele B, Macchia V, Mazzacca G. Diamine oxidase in rat small bowel: distribution in different segments and cellular location. Enzyme 1984; 31 : 217-20.

5 Shakir KM, Margolis S, Baylin SB. Localization of histaminase (Diamine oxidase) in rat small bowel intestinal mucosa: site of release by heparin. Biochem Pharmacol 1977; 26: 2343-7.

6 D'Agostino L, Ciacci C, Daniele B, Barone MV, Sollazzo R, Mazzacca G. Postheparin plasma Diamine oxidase in subjects with small bowel mucosa atrophy. Dig Dis Sci 1987; 32: 313-17.

7 Guedon C, Schmitz J, Lerebours E, et al. Decreased brush border hydrolase activities without gross morpho- logic changes in human intestinal mucosa after prolonged total parenteral nutrition of adults. Gastroenterology 1986; 90: 373-8.

8 Stevenson MR, Fierstein JS. Circadian rhythms of intestinal sucrase and glucose transport: cued by time of feeding. Am J Physiol 1976; 230: 731-5.

9 Saito M, Murakami E, Suda M. Circadian rhythms in disaccharidases of rat small intestine and its relation to food intake. Biochim Biophys Acta 1976; 421: 177-9.

10 Nishida T, Saito M, Suda M. Parallel between circadian rhythms of intestinal disaccharidases and food intake of rats under constant lighting conditions. Gastroenterology 1978; 74: 224-7.

11 Fujmoto M, Kanaya A, Nakabou Y, Hagihira $H$. Circadian rhythm in the ornithine decarboxylase activity of rat small intestine. J Biochem 1978; 83: 237-42.

12 Bachrach $U$. The induction of ornithine decarboxylase in normal and neoplastic cells. In: Gaugas JM ed. Polyamines in biomedical research. Chichester, New York, Brisbane, Toronto: John Wiley, 1980: 81-107.

13 Djuhruus R. Ornithine decarboxylase (EC 4.1.1.17) assay based upon the retention of putrescine by a strong cation-exchange paper. Anal Biochem 1981; 113: 3525.

14 Dahlqvist A. Method of assay of intestinal disaccharidases. Anal Biochem 1964; 7: 18-25.

15 Lowry OH, Rosebrough NJ, Farr AL, Randall RJ. Protein measurement with the Folin phenol reagent. $J$ Biol Chem 1951; 193: 265-75.

16 Luk GD, Baylin SB. Ornithine decarboxylase in intestinal maturation, recovery and adaptation. In: Robinson JWL, Dowling RH, Riecken EO eds. Mechanisms of intestinal adaptation. Lancaster: MTP Press, 1982: 6578.

17 Weekly JM, Vaughan WP. Plasma levels of the polyamine degrading enzyme Diaminoxidase (DAO) can be used to monitor the G.I. epithelial toxicity of the polyamine synthesis inhibitor Difluoromethyl Ornithine (DFMO). [Abstract]. Clin Res 1985; 33: 855A.

18 Luk GD, Hamilton SR, O'Ceallaigh D, Smith J, Natuzzi E, Baylin SB. Azoxymethane induces a generalized biphasic increase in intestinal Ornithine decarboxylase during colon carcinogenesis. [Abstract]. Gastroenterology 1982; 82: 1121.

19 Williamson RCN, Rainey JB. The relationship between intestinal hyperplasia and carcinogenesis. Scand $J$ Gastroenterol 1984; 19 Supp. 104: 57-76. 